\title{
Rio-Paris: primórdios da publicação da Literatura Brasileira chez Garnier!
}

\author{
Rio-Paris: beginnings of Brazilian Literature by Garnier's publishers
}

\section{Lúcia Granja}

Universidade Estadual Paulista “Júlio de Mesquita Filho", campus de São José do Rio Preto, SP, Brasil

Resumo: Este artigo dá notícias de nossas últimas pesquisas sobre as atividades de BaptisteLouis Garnier, livreiro e editor francês estabelecido no Rio de Janeiro, em suas relações com o mundo editorial francês: métodos, procedimentos, livros, autores e editores. As trocas culturais entre esses dois sistemas ajudaram a consolidar o cânone dos autores e obras da Literatura Brasileira no século XIX e o estudo dessas relações poderá detalhar algumas informações que, até hoje, forneceu-nos a história da Literatura Brasileira, contribuindo para um maior conhecimento do processo de produção e circulação de obras literárias no Brasil.

Palavras-chave: História do Livro. História literária. Literatura Brasileira. Globalização da cultura. Baptiste-Louis Garnier. Machado de Assis. José de Alencar.

Abstract: This article brings to light the latest research on the activities of Baptiste-Louis Garnier, French bookseller and publisher established in Rio de Janeiro, in his relations with the French publishing world: methods, procedures, books, authors and publishers. Cultural exchanges between these two systems helped to consolidate the canon of authors and works of Brazilian Literature in the nineteenth century. The study of these relationships can give full account of some information scholars have provided us and contributes to a better understanding of the process of production and circulation of literary works in Brazil.

Keywords: History of books. Literary history. Brazilian Literature. Globalization of culture. Baptiste-Louis Garnier. Machado de Assis. José de Alencar.

1 Este artigo é resultado parcial de minha participação no Projeto Temático Fapesp "A circulação transatlântica do impresso: a globalização da cultura no século XIX", que se estenderá até o ano de 2014. Ele apresenta uma pesquisa em elaboração, mas na qual já existem resultados que penso devam ser divulgados. Escrito após duas estadias de pesquisa na França, o artigo corresponde a uma versão bastante modificada e ampliada de uma das partes do texto que apresentei na USP, "Garnier no Brasil: esta história se faz com homens e livros", por ocasião do colóquio "A circulação transatlântica dos impressos", ECA, USP, 27-29 de agosto de 2012. Agradeço à Unesp e à Fapesp pelas bolsas concedidas para pesquisa no exterior, respectivamente, nos meses de junho-julho de 2012 e outubro de 2012 a janeiro de 2013. Agradeço ainda ao Prof. Jean-Yves Mollier pela amizade e interesse com que me acolheu no Centre d'Histoire Culturelle des Societés Contemporaines, Université de Versailles à St. Quentin-en-Yvelines, entre junho de 2012 e fevereiro de 2013. 
Voltar a Baptiste-Louis Garnier e ao estudo dos vínculos entre mundo e mercado editoriais francês e brasileiro poderá detalhar, e até mesmo retificar, algumas informações que, até hoje, forneceu-nos a história da Literatura Brasileira, contribuindo para um maior conhecimento do processo de produção e circulação de obras literárias escritas no Brasil do XIX. O livreiro e editor francês foi aquele que, nas palavras de Ernesto Senna (2006), dominou o comércio de livros no Rio de Janeiro na segunda metade do século XIX e que, como nos lembra Hallewell (2005, p. 217) com precisão, teve "a seu crédito a publicação de 665 obras de autores brasiLúcia leiros". Ao longo de sua trajetória de mais de cinquenta anos no Brasil, foi Granja condecorado por D. Pedro II com a comenda da Ordem da Rosa, graças aos serviços prestados às letras brasileiras, uma vez que, além de fornecedor de livros franceses e estrangeiros em geral, e de variada gama, foi o editor de grande parte dos nossos escritores do XIX.

Acompanhando de perto a atividade editorial de Garnier, principalmente em seus primórdios, observamos que os escritores brasileiros na segunda metade do século XIX logo perceberam as oportunidades que a empresa lhes ofereceria. Machado de Assis, por exemplo, na série de crônicas "Ao acaso", publicadas no Diário do Rio de Janeiro entre junho de 1864 e meados de 1865, fala-nos inúmeras vezes das ações e edições de Baptiste-Louis Garnier. Nelson Schapochnik já observara que:

\footnotetext{
Salta às vistas, entre as crônicas de Machado, a quantidade de referências ao seu editor [...]. Entretanto, inexiste alguma referência denegadora dos préstimos do editor. Os elogios são escancarados e as intervenções parecem ser muito mais do que meras resenhas dos lançamentos [...]. (SCHAPOCHNIK, 2010, p. 14).
}

Mas o que seriam essas intervenções que se apresentam como mais do que meras resenhas dos lançamentos de livros? Especialmente na série "Ao acaso", o cronista Machado de Assis vai muito além da "revista literária" da semana quando se refere a livros e autores. Revisitando esses textos, encontramo-nos diante de uma pequena campanha de promoção do trabalho de Garnier como editor, após quase duas décadas de atividades no Brasil, ligadas, principalmente, ao comércio de livros. Essas crônicas de Machado, aqui rapidamente mencionadas, mostram-nos que Baptiste-Louis Garnier encaminha uma política editorial para sua casa semelhante à dos seus irmãos e à de outros livreiros 
importantes de Paris àquela época, como podemos verificar também ao analisar os catálogos dessas editoras (DUTRA, 2010), dos quais constam a publicação de obras completas, coleção de obras didáticas, eleição dos clássicos de uma literatura nacional, entre outros. Diz-nos Machado de Assis em outubro de 1864:

Os Cantos fúnebres encontrarão da parte do público brasileiro o acolhimento a que têm direito. Tanto mais devem procurar o novo livro quanto que este volume é o sexto da coleção das obras completas do poeta, que o Sr. Garnier vai editar.

0 volume que tenho à vista é nitidamente impresso. A impressão é feita em Viena, aos olhos do autor, garantia para que nenhum erro possa escapar; sendo esta a edição definitiva das obras do poeta é essencial que ela venha limpa de erros.

Um bom livro, uma bela edição, - que mais pode desejar o leitor exigente? (MACHADO DE ASSIS, 1864, p.1).
Rio-Paris: primórdios da publicação da

Literatura

Brasileira

chez Garnier

Vemos que, ao mencionar o novo volume de Gonçalves de Magalhães, o cronista ressalta para os seus leitores, primeiramente, a qualidade da edição: impressão nítida, feita na Europa; sem erros, composta sob as vistas do escritor que as acompanhava de perto. Mas isso ainda não é tudo. o público brasileiro, conforme aconselha o cronista, deveria acolher como é de direito essa obra, o que nos coloca, em princípio, diante dos vértices da literatura nacional (CANDIDO, 1986): para a obra de Magalhães existiria um público leitor definido; para o público brasileiro, havia autores significativos, cuja obra deveria ser colecionada, uma vez que o livro em questão corresponde ao sexto volume das Obras completas do escritor, que Garnier trazia à luz em edição definitiva. Ao que parece, então, a análise dos comentários machadianos à luz das ações de Garnier pode detalhar a ideia do sistema literário, à medida que nos mostra que o editor e o crítico-cronista se completam na delimitação e divulgação de uma política editorial para a Literatura Brasileira, assim como nas condições de colocar em prática essa política. No limite, estamos diante do processo de configuração do campo artístico brasileiro, que escrevem, juntos e entre si, Machado, Garnier e todos os outros autores e atores do período (BOURDIEU, 2001).

Mas antes mesmo de configurarem em torno de Garnier esse projeto nacional, já de saída, como ressalta Machado de Assis na crônica, os literatos brasileiros tiveram uma motivação importante para se ren- 
derem ao editor francês: a qualidade das impressões. José de Alencar, por exemplo, queixou-se algumas vezes das dificuldades que teve no momento em que tentou publicar, às próprias expensas, seus romances, ou seja, antes dos contratos que ele assinou com a casa Garnier. Em sua autobiografia intelectual, tão citada pelos historiadores e estudiosos do livro, enunciou: "Se eu tivesse a fortuna de achar oficinas bem montadas com hábeis revisores, meus livros sairiam mais corretos; a atenção e o tempo por mim despendidos em rever, e mal, provas truncadas, seriam melhor aproveitados [sic] em compor outra obra" (ALENCAR, Lúcia 1955, p. 69). Da mesma forma, no posfácio da segunda edição de um dos Granja seus principais romances, Iracema, ele nos diz:

Dali por diante, na editora de Garnier, os problemas com a composição dos livros seriam cada vez menores, pois a qualidade dos produtos era uma das estratégias de venda e de ocupação do mercado brasileiro. A Vulgata, por exemplo, publicada em 1865 e traduzida diretamente para o português pelo Padre Antonio Pereira Figueiredo, era anunciada nos jornais e catálogos como "nitidamente impressa e suntuosamente encadernada em Paris" (HALLEWELL, 2005, p. 200).

Aproveitando-se de todas as oportunidades para construir seu mundo comercial, que ligava a França e o Brasil por uma ponte de livros, Garnier manteve, morando em Paris, um revisor de provas para a sua editora, o jornalista José Lopes da Silva Trovão. Este último fora correspondente de $O$ Globo e se vira em dificuldades após o fechamento do jornal (SENNA, 2006; HALLEWELL, 2005). Todas essas ações, é claro, só aumentavam o prestígio da livraria e editora diante desse que era o seu público mais importante, os homens de letras brasileiros ou instalados no Brasil, como era o caso de tantos portugueses àquela época.

Para reforçar o nosso conhecimento a respeito dos investimentos de Garnier na publicação de livros em português destinados a circular no Brasil, recentemente, um documento jamais mencionado veio a nos mos- 
trar que as ações e os cuidados de Garnier com a publicação desses livros na França foram ainda mais importantes do que pudéramos, até então, avaliar. Um contrato firmado entre Garnier e Jules Henri Gueffier em 10 de fevereiro de 1864 esclarece que este último foi recrutado por Garnier para prestar, em Paris, serviços de impressor, representá-lo junto às livrarias e, quando necessário, atuar como tradutor. Citamos, a seguir, um trecho do longo documento manuscrito, do qual mantivemos a pontuação original:

Hoje dez de fevereiro de mil oitocentos e sessenta e quatro diante de nossos chanceleres da legação da França no Brasil, cônsul honorário

Compareceram - o Sr. Baptiste-Louis Garnier livreiro residente no Rio de Janeiro à Rua do Ouvidor $\mathrm{n}^{\mathrm{0}} 69$ - por um lado - e Jules Rio-Paris: primórdios da publicação da

Literatura

Brasileira

chez Garnier

Henri Gueffier tipógrafo residente no Rio de Janeiro à Rua da Assembléa $n^{\circ} 89$ - de outro lado os quais depositaram na chancelaria da legação um dos originais de um escrito assinado entre eles contendo as condições de um acordo passado entre eles para trabalhos e tudo o que se relaciona à impressão livraria e tradução. [...]

Entre os abaixo-assinados Sr. Baptiste-Louis Garnier, residente no Rio de Janeiro - e o Sr. Jules Henri Gueffier, residente presentemente no Rio de Janeiro, mais devendo ir se fixar em Paris - foi contratado o que se segue:

$1^{\circ}$ - O Sr. Jules Henri Gueffier se compromete a trabalhar em Paris por nove anos consecutivos, começando em primeiro de abril de mil oitocentos e sessenta e quatro e cessando em trinta e um de maio de mil oitocentos e setenta e três, com exclusividade para Baptiste-Louis Garnier, na qualidade de empregado, para trabalhos de impressão, de livraria e de tradução que esse último julgar necessários.

(Arquivos do Ministère des Affaires Étrangères, La Courneuve, França, Actes Notariés, Rio de Janeiro, 1861-1873, tradução nossa). ${ }^{2}$

2 “Aujourd'hui dix février de mille huit cent soixante quatre - par devant nous chanceliers de la légation de la France au Brésil, consul honoraire/Ont comparu [sic] - M. Baptiste Louis Garnier libraire demeurant à Rio de Janeiro Rua do Ouvidor $\mathrm{n}^{0} 69$ - d'une part - et Jules Henri Gueffier typographe demeurant à Rio de Janeiro Rua da Assemblea $\mathrm{n}^{\circ} 89$ - d'autre part lesquels ont déposé en la chancellerie de la légation l'un des originaux d'un écrit sous signatures privées contenant les conditions d'un engagement passé entre eux pour des travaux et intérêts d'imprimerie librairie et traduction./[...]/ Entre les soussignés M. Baptiste-Louis Garnier, demeurant à Rio de Janeiro - Et M. Jules Henri Gueffier, 
O contrato enuncia ainda uma meia dúzia de cláusulas, que tratam do pagamento de Gueffier (quinhentos francos por mês, ou duas vezes o salário de um professor primário, na França, àquela época ${ }^{3}$ ), das condições de rescisão do contrato, da possibilidade de renovação, entre outros. Estamos diante de mais uma prova de que, nas oficinas tipográficas francesas, a literatura escrita no Brasil rodava nas prensas, o que nos confirma, ainda uma vez, que Paris era a "capital editorial do mundo de lusófono na primeira metade do século XIX", como o definiu Diana Cooper-Richet (2009, p. 535-555). Se esse fato é importantíssimo para nos mostrar que Paris, e a Lúcia França em geral, foi fundamental na história da produção e da circulação Granja do impresso em escala mundial no XIX, em várias línguas, ele toca ainda em uma questão mais delicada, que merece uma investigação específica: a de que os esquemas de produção e circulação do livro, e do impresso em geral, não se limitavam aos espaços nacionais. Na realidade, no século XIX,

[...] a entrada na modernidade, que coincide com a revolução industrial e com a intensificação das transferências bilaterais e trocas internacionais, estabelece, bem antes do mundo de hoje, um movimento irreversível de globalização, que, além de suas consequências políticas e econômicas, caracteriza-se de maneira evidente pela uniformização de práticas e modos de vida. [...]. (VAILLANT, 2009, p. 115, tradução nossa). ${ }^{4}$

Assim sendo, a edição e impressão em Paris - além da possibilidade de o livro, objeto material, circular na capital francesa - são fatos que nos esclarecem como, em meados dos anos 1860, os escritores brasileiros, ao lado de um bom editor, começaram a alimentar o sonho de ali fazerem presentes os seus textos um dia, não apenas na prensa dos ateliês, mas também nas mãos dos leitores, melhor ainda se traduzidos para o francês. No caso de Alencar, a propósito, esse projeto estava a caminho

demeurant présentement à Rio de Janeiro mais devant aller se fixer à Paris - il a été dit et convenu ce que suit:/- $1^{\circ}$ - Mr. Jules Henri Gueffier s'engage à travailler à Paris pendant neuf années consécutives, commençant au premier avril mille huit cent soixante quatre et finissant au trente et un mai mil huit cent soixante treize, exclusivement pour Baptiste-Louis Garnier, en qualité d'employé, pour tous les travaux d'imprimerie, de librairie et de traduction que celui-ci jugera nécessaires [...]".

3 Agradeço ao Prof. Jean-Yves Mollier pelos termos da comparação de valores.

4 “[...] l'entrée dans la modernité, qui coïncide avec la révolution industrielle et avec l'intensification des transferts bilatéraux et deséchanges internationaux, engage, bien avant le monde d'aujourd'hui, un mouvement irréversible de mondialisation qui, outre ses conséquences politiques et économiques, se caractérise de la façon la plus visible par l'uniformisation des pratiques et des modes de vie. [...]". 
naquela época. Em texto ainda inédito, Ilana Heineberg levanta e se interroga sobre algumas das traduções de 0 Guarani: a de 1863, em forma de folhetim no jornal Le Brésil, publicado no Rio de Janeiro, com tradutor desconhecido e anônimo; a de 1889, também em forma de folhetim no jornal parisiense Les Droits de l'Homme, traduzido por Louis-Xavier de Ricard (1843-1911); a de 1902, versão em livro da tradução de Ricard, publicada pela editora Tallandier; e, ainda, a de 1947, tradução de Vasco de Lacerda, publicada pela editora La Sixaine (HEINEBERG, texto inédito) ${ }^{5}$.

Podemos, então, imaginar que a década de 1860 trouxe um desafio aos nossos homens de letras, expresso, aliás, no célebre ensaio de Machado de Assis, "Notícia atual da Literatura Brasileira. Instinto de nacionalidade" (publicado, como sabemos, no periódico Novo Mundo, em Nova York, em 24 de março de 1873), no qual o crítico constata que "conviria examinar se possuímos todas as condições e motivos históricos de uma nacionalidade literária", mas diz ter, como principal objetivo, atestar "o fato atual [...] o geral desejo de criar uma literatura mais independente" (MACHADO DE ASSIS, 2008, p. 1204). Essa literatura deveria se respaldar no "sentimento íntimo" do escritor, "que o torne homem de seu tempo e de seu país, ainda quando trate de assuntos remotos no tempo e no espaço" (MACHADO DE ASSIS, 2008, p. 105), na conhecidíssima formulação machadiana. A ideia da literatura mais independente, associada ao fato de o escritor ser exigido a se sentir homem de seu tempo e de seu país, permite-nos afirmar que esse debate estético e ideológico dialoga diretamente, como vimos procurando demonstrar, com a situação material da edição dos textos: se a imaginação, personagens, situações, entre outros, eram brasileiros, os "caminhos dos livros" já não o eram. Cabia, então, ao escritor, trabalhar os "legados" da Literatura Brasileira, compreendendo-os como sendo tão brasileiros quanto universais (MACHADO DE ASSIS, 2008, p. 1205).

Para exemplificar a relação entre a profissionalização das edições e a circulação (ainda que modesta) "internacional” da Literatura Brasileira, empreendemos, a seguir, uma análise de algumas das primeiras edições de o Guarani. Desde que, a partir da segunda edição em livro, o romance passou a ser editado chez Garnier, o que se deu em 1864, observamos que o livreiro e editor opera com uma lógica de mercado bastante próxima à europeia. 0 Guarani ganhou, assim, materialmente, o espírito das edições preparadas

5 Agradeço a Ilana Heineberg por me dar acesso ao texto e permitir que eu o cite. 
àquela época por Michel Lévy na França, acompanhada também por outros editores, e por Baptiste-Louis Garnier além-mar, que seguia de perto as tendências comerciais e propagandísticas do mercado europeu, transpondo-as ao brasileiro, como já mencionou Hallewell (2005). Mas, para além disso, a análise comparativa das edições mostra-nos que o livreiro francês instalado no Brasil não imitou apenas o formato da edição de Lévy, mas trouxe, para suas coleções, o mesmo espírito de apresentação e divulgação das obras, adaptando sua comercialização ao mercado brasileiro. Assim, como vemos pela figura 1, Garnier trouxe a público duas novas edições de 0 Gua-

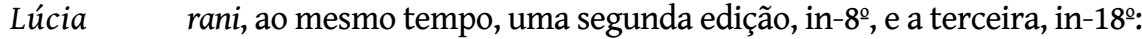

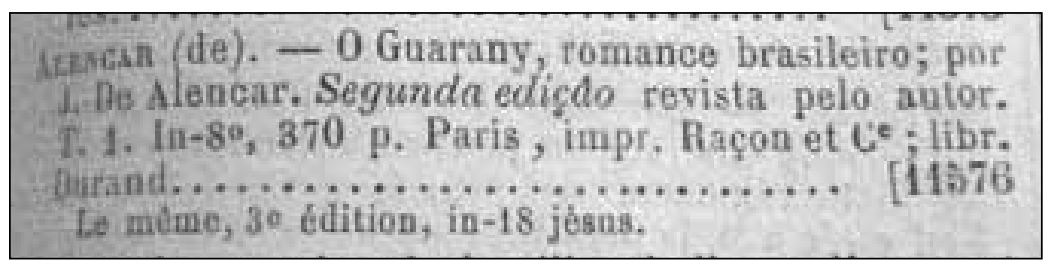

Figura 1 - Bibliographie de la France. Journal general de l'imprimerie et de la librairie de la librairie, no . 52, 24 dez. 1864

Fonte: Bilbiothèque Nationale de France, catálogo geral.

A publicação desses dados no periódico dos impressores de Paris, como vemos na imagem, combinada à análise dos exemplares, mostra-nos que, em 1864, ao se fazer, ao mesmo tempo, duas edições do romance, de modo a aproveitar a mesma composição tipográfica, endereça-se a obra a dois públicos diferentes, ou, ao menos, a dois usos diferentes. Com os livros em mãos, podemos observar que a segunda edição de 0 Guarani foi feita em papel de boa qualidade, formato in- $8^{\circ}$, costurada, com capa luxuosa, em papel cartão adequado e resistente e, pelo que consta da contracapa da terceira edição, vemos que ela era vendida, no Brasil, a 4 mil réis. Já a terceira edição, feita no formato popular in-18º, foi impressa em papel bastante ordinário, capa em papel colorido de baixa gramatura, trazendo nas contracapas, como assinalamos anteriormente, extratos dos catálogos de Garnier; ela era vendida a 2 mil réis.

Embora haja diferenças e semelhanças, vemos que o método de Baptiste-Louis Garnier é inspirado nas ações de Michel Lévy. Este último criou na França, em meados dos anos 1850, um novo sistema de produção e venda de livros, que equivaleu a uma "revolução no preço do livro 
na França" (MOLLIER, 1994, p. 267), a "Collection Michel Lévy". Por esse sistema, barateou completamente as edições, utilizando o formato in-18º, fazendo tiragens de até 6 mil exemplares, que vendia a 1 franco a unidade (brochuras) e a 1,50 franco a unidade (edições encadernadas costuradas). Ele comprava os direitos sobre as obras dos autores, pagando-os de antemão, e desenvolvia uma forte rede de distribuição (em livrarias e quiosques nas estações de trem), a qual assegurava as vendas de tão grandes tiragens (MOLLIER, 1994). Em termos de comparação, temos que as tiragens de Garnier, informação que ainda não pudemos confirmar completamente, giravam em torno de trezentos exemplares nessa época; 2.400 réis, em 1864, não configuram edições baratas ${ }^{6}$, mas havia, como no caso de Lévy, a oferta da edição de melhor qualidade e da edição "popular", impressa no mesmo formato e na mesma tipografia que usava Lévy, a de Simon \& Raçon, em Paris; a rede de livrarias e quiosques era inexistente no Brasil, mas Garnier, segundo informações que também precisam ainda ser mais bem esclarecidas, enviava os seus produtos para todo o país. Métodos comparáveis, diferentes públicos, diferentes sociedades e diferentes formas de acesso à leitura. Qual teria sido o objetivo de Garnier ao planejar e executar as duas edições concomitantes? O que sabia ele sobre o público leitor, e consumidor, da Literatura Brasileira, real e potencial, que, hoje em dia, nós ignoramos? Ambos, Lévy e Baptiste-Louis Garnier, compravam os direitos dos autores em definitivo, logo de saída, e procuravam, na tiragem, o lucro. Mas Garnier, que praticava tiragem bem menor que a do modelo francês, misturava esse sistema a um mais antigo, anterior à popularização do livro na França, no qual esse objeto custava caro. Dava a imprimir, como Lévy, suas edições, em Paris, às tipografias habituadas a trabalhar em língua portuguesa (Simon \& Raçon, por exemplo, como vimos na Figura 1) e colocava-as à venda, ainda em Paris, na Livraria Durand (como vimos na Figura 1), e não na casa comercial de seus irmãos.

Se ainda é cedo para responder às perguntas que fizemos anteriormente, podemos, desde já, levantar alguns pontos de reflexão. As mudanças estéticas operadas no romance brasileiro por José de Alencar e Machado de Assis, por exemplo, não podem ser lidas desvinculadas do diálogo constante com as novidades "do tempo e do país", as novidades materiais inclusive. Esse olhar lança uma indagação diferenciada em

6 Lemos no Diário do Rio de Janeiro de 14 de julho de 1864 que a assinatura anual desse jornal diário saía por 24 mil réis; já um colete de seda masculino custava entre 3 e 5 mil réis na loja nada popular "A la place de la Concorde", na Rua da Assemblea. 
relação à composição dos perfis de mulher de Alencar, nos anos $1860 \mathrm{e}$ 1870, assim como em relação aos romances machadianos dos anos 1870 . No caso de Alencar, pode ser que a adoção do romance e de suas formas de acatar as ideologias (SCHWARZ, 2000) tenha tido vista a uma possível inserção europeia do romance urbano brasileiro, caminho aberto pelas idas e vindas dos livros, desde o seu processo de composição. Para Machado de Assis, em relação aos romances que escreveu a partir de 1872, o mesmo objetivo alencariano estaria sendo cumprido, à medida que o escritor parece procurar a forma exata de contemplar o nacional, Lúcia unindo-o ao "desejo de criar uma literatura mais independente". Teria Granja estado em jogo, dessa forma, no caso de ambos os escritores, a possibilidade de circular, em português ou em tradução, nas oficinas e livrarias francesas, o que teria trazido em definitivo para o romance (e para o conto, no caso machadiano) a vida urbana carioca, desde as representações históricas (CHARTIER, 1985) até os negócios e limites sociais das relações pessoais e civis.

Outras pistas da presença, na França, dessa literatura que se afirmava como brasileira são os catálogos da livraria Garnier, conservados na Bibliothèque Nationale de France (BNF), já analisados, como mencionamos anteriormente, por Eliana Dutra (2010). Lendo-os no contexto da circulação do impresso, se essas pequenas brochuras ali estão, é porque elas próprias foram impressas na França. Nesse caso, podemos pensar que tinham o objetivo de atingir não apenas o público brasileiro, retornando ao Rio, mas também a importante comunidade lusófona estabelecida em Paris. A análise detalhada de um desses catálogos, o de número 23 , do qual damos pequena amostra aqui (Figura 2), ajuda-nos a reconstruir a história dos livros brasileiros de Baptiste-Louis Garnier no território francês. Esse documento foi publicado, certamente, após 1863, pois anuncia uma das principais inovações de Garnier, o Jornal das Famílias, cujo primeiro exemplar saiu em janeiro de 1863. O pequeno caderno conservado na BNF é um extrato do catálogo 23 completo, ${ }^{7}$ correspondendo às principais obras comercializadas pelo livreiro francês, como podemos observar pelo título da capa (Figura 2):

7 Verificamos a íntegra do catálogo, sob a forma de dados digitados, junto ao material recolhido pelo Projeto Temático Fapesp "Os caminhos do romance", coordenado por Marcia Abreu. 


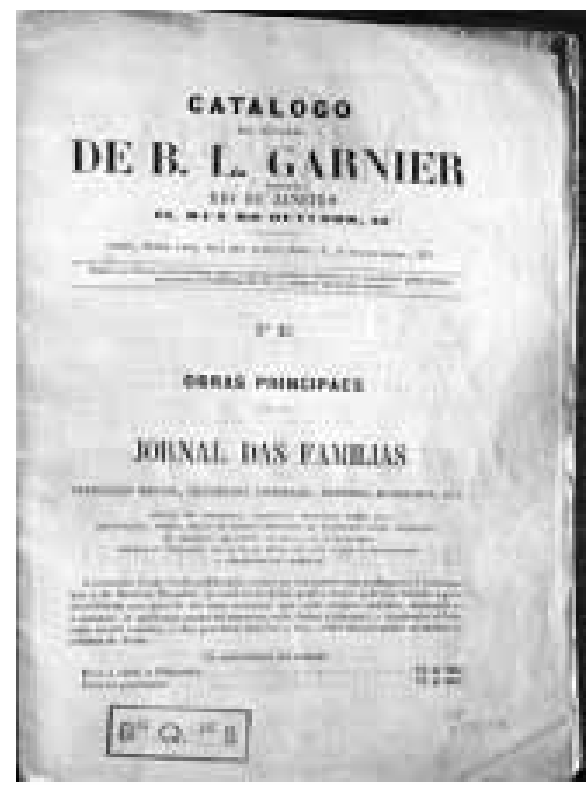

Rio-Paris: primórdios da publicação da

Literatura

Brasileira chez Garnier

Figura 2 - Catálogo da Livraria B. L. Garnier, no Rio de Janeiro, 69, Rua do Ouvidor, no 23, sem data de publicação

Fonte: Bilbiothèque Nationale de France, série $8^{\circ} \mathrm{Q} 10 \mathrm{~B}$.

A brochura organiza-se, agora inteiramente em português, em sete seções, da seguinte maneira: Livros de Educação, Clássicos de Instrução etc.; Medicina, Homeopatia, Magnetismo; Poesias, Literatura; Romances, Novelas etc.; Peças de teatro; e Obras diversas. Aparentemente, naquele tempo, o editor dos brasileiros investia fortemente em obras de cunho didático e em poesia, pois esse tipo de livros correspondia à maior parte dos títulos que o próprio Garnier publicava. Voltando ao início deste artigo, não estranha, então, que a crônica de Machado de Assis, em 1864, observe, reforçando essa linha editorial, que a poesia brasileira tinha força de qualidade e volume para ser colecionada. Focando os livros da seção "Poesia e Literatura", a enumeração a seguir dá-nos uma ideia geral das obras que Garnier apenas vendia e daquelas em que trabalhara como editor, como pudemos verificar em vários arquivos e bibliotecas, e destacamos aqui em negrito, mantendo a ortografia do catálogo: Assumpção (A), poema composto [...] por Fr. Francisco de S. Carlos; nova edição precedida da biographia do autor e d'unjuizo critico sobre a obra pelo conego Dr. J.C.Fernades Pinheiro. [...]; Cinzas d'un livro, fragmentos d'un livro inedito, por Bruno Seabra; Dores e flores, poesias de Augusto Emilio Zaluar; Flores e fructos, poesias de Bruno Seabra; Flores entre espinhos, contos 
poeticos por J. Norberto de S. S.; Flores sylvestres, poesias, por F. L. Bittencourt Sampaio [...]; Folhas Caídas, Gonzaga; Harmonias Brasileiras, cantos nacionaes, colligidos e publicados por Antonio Joaquim de Macedo Soares; O Livro de meus amores, poesias eróticas de J. Norberto de Souza Silva [...]; Magalhaes (Dr. J. G. de). Factos do espirito humano, philosophia [...]; Magalhaes (Dr. J. G. de). Suspiros poeticos e saudades [...]; Marilia de Dirceu, por Thomaz Antonio Gonzaga, nova edição dada pelo Sr. J. Norberto de Souza Silva, com estampas [...]; Meando Poético; Novaes (Faustino Xavier de) Poesias, segunda edição; Novaes (Faustino...) Novas Poesias acompaLúcia nhadas de um juízo crítico de Camilo Castelo Branco [...]; Obras do BachaGranja rel M. A. Alvares de Azevedo, precedidas de um discurso biographico, e acompanhadas de notas, pelo Dr. D. Jacy Monteiro, terceira edição correta e augmentada com as obras ineditas, e um apendice contendo discursos e artigos feitos por occasião da morte do autor [...]; Obras poeticas de Manoel Ignacio da Silva Alvarenga (Alcindo Palmireno), colligidas, annotadas e precedidas do juizo critico dos escriptores nacionaes e estrangeiros, e de uma noticia sobre o autor, e acompanhada de documentos historicos, por J. Norberto de Souza Silva; O Outono; Peregrinações à província de São Paulo, de Augusto Emilio Zaluar; Poesias Selectas de autores mais illustrados antigos e modernos [...]; Revelações. Poesias de Augusto Emilio Zaluar [...]; Romanceiro (O), por A. Garrett; Poesias ternas e amorosas; Sombras e sonhos, poesias de José Alexandre Teixeira de Mello; Urania, cânticos; Urania, collecção de cem poesias inéditas, por D. J. G. de Magalhães.

Assim sendo, entre os 25 livros da seção "Poesia e literatura" que anunciava Garnier nesse catálogo, 12, ou quase $50 \%$ deles, correspondem aos que ele mesmo publicara, tendo-os composto nas oficinas francesas. Considerando que a sua atividade como "editor da literatura Brasileira" estava no início, avaliamos melhor a energia empregada nesse projeto e a relevância dessa atividade editorial para a configuração da vida literária no Brasil da época, considerando a circulação (nacional e internacional) dos textos, a profissionalização dos escritores (LAJOLO; ZILBERMAN, 1996) e mesmo as escolhas e reavaliações estéticas dos nossos homens de letras.

A investigação prossegue por esses rumos. Ator no processo das transferências culturais, esse editor-livreiro pode ser considerado uma das peças fundamentais da cultura brasileira, mesmo que muitas de suas práticas e ações permaneçam, até hoje, desconhecidas. 


\section{Referências}

ALENCAR, José de. Obra completa. Rio de Janeiro: Aguilar, 1958. v. 3.

Como e porque sou romancista. Salvador: Progresso, 1955.

BOURDIEU, Pierre. A economia das trocas simbólicas. 5. ed. Tradução de Sérgio Miceli. São Paulo: Perspectiva, 2001.

CANDIDO, Antonio. Formação da Literatura Brasileira. Belo Horizonte: Itaiaia, 1986. 2v.

Rio-Paris: primórdios da publicação da

Literatura

Brasileira

chez Garnier

CHARTIER, Roger. A história cultural: entre práticas e representações. 2. ed. Tradução de Maria Manuela Galhardo. Lisboa: Difel, 1985.

COOPER-RICHET, Diana. Paris, capital editorial do mundo lusófono na primeira metade do século XIX. Revista Varia História, n. 42, p. 539-555, jul./dez. 2009.

DUTRA, Eliana de Freitas. Leitores de além-mar: a Editora Garnier e sua aventura editorial no Brasil. In: ABREU, Marcia; BRAGANÇA, Aníbal (Org.). Impresso no Brasil: dois séculos de livros brasileiros. São Paulo: Ed. da Unesp, 2010. p. 67-88.

HALLEWELL, Laurence. 0 livro no Brasil. 2. ed. revista e ampliada. São Paulo: Edusp, 2005.

HEINEBERG, Ilana. Peri com sotaque francês: um estudo preliminar de três traduções de $O$ Guarani no século XIX. Texto inédito. Mimeografado.

LAJOLO, Marisa; ZILBERMAN, Regina. A construção do leitor. In: ; ___ A formação da leitura no Brasil. São Paulo: Ática, 1996. p. 13-64.

MACHADO DE ASSIS, J. M. Ao acaso. Diário do Rio de Janeiro, Rio de Janeiro, 17 out. 1864. 
MACHADO DE ASSIS, J. M. Notícia atual da Literatura Brasileira. Instinto de nacionalidade. In: obra completa em quatro volumes. 2. ed. Organização de Aluízio Leite, Ana Lima Cecílio, Heloísa Jahan. Rio de Janeiro: Aguilar, 2008. v. 3, p. 1.203-1.211.

MOLLIER, Jean-Yves. Michel \& Calmann Lévy, ou la naissance de l'édition moderne, 1836-1891. Paris: Calman \& Lévy, 1994.

SCHAPOCHNIK, Nelson. Malditos tipógrafos. In: SEMINÁRIO SOBRE Lúcia LIVRO E HISTÓRIA EDITORIAL, 1., 2004, Rio de Janeiro. Anais... Rio de Granja Janeiro: UFF/FCRB, 2004. Disponível em: <http://www.livroehistoriaeditorial.pro.br/pdf/nelsonschapochnik.pdf.> Acesso em: 10 jul. 2010.

SCHWARZ, Roberto. Ao vencedor as batatas: forma literária e processo social nos inícios do romance brasileiro. São Paulo: Ed. 34, 2000. (Coleção Espírito Crítico).

SENNA, Ernesto. O velho comércio do Rio de Janeiro. Rio de Janeiro: G. Ermakoff Casa Editorial, 2006. (reedição da edição de 1910, publicada pela Garnier).

VAILLANT, Alain. Identités nationales et mondialisation médiatique. Étude de titrologie comparée (Mexique, France, Grand-Bretagne, Espagne - 1821-1861). In: ANDRIES, Lise; LA TORRE, Laura Suaréz de (Org.). Impressions du Mexique et de France. Impresiones de México y de Francia. Éditions de la Fondation Maison Sciences de l'Homme, 2009. p.115-144.

\section{Arquivos e periódicos}

Archives Diplomatiques du Ministère des Affaires Étrangers (França): Actes Notariés, Rio de Janeiro, 1861-1873.

Bibliothèque Nationale de France: Bibliographie de la France. Journal général de l'imprimerie et de la librairie de la librairie, n. 52, 24 dez. 1864. 
Bibliothèque Nationale de France: Catálogo da Livraria B. L. Garnier, no Rio de Janeiro, 69, Rua do Ouvidor, no 23, sem data de publicação, série $8^{\circ} \mathrm{Q} 10 \mathrm{~B}$.

Diário do Rio de Janeiro, Rio de Janeiro, 1864-1865. Consultados nas imagens de microfilmes adquiridas pelo Projeto Temático Fapesp "A circulação transatlântica dos impressos: a globalização da cultura". Também disponível na Hemeroteca Digital Brasileira: <http://hemerotecadigital.bn.br/diário-do-rio-de-janeiro/094170>.

\author{
Rio-Paris: \\ primórdios da \\ publicação da \\ Literatura \\ Brasileira \\ chez Garnier
}

